Journal for ImmunoTherapy of Cancer

\section{IL-15 superagonist RLI has potent immunostimulatory properties on NK cells: implications for antimetastatic treatment}

To cite: Desbois M, Béal C, Charrier M, et al. IL-15 superagonist RLI has potent immunostimulatory properties on NK cells: implications for antimetastatic treatment. Journal for ImmunoTherapy of Cancer 2020;8: $\mathrm{e} 000632$. doi:10.1136/jitc-2020-000632

- Additional material is published online only. To view please visit the journal online (http://dx.doi.org/10.1136/jitc2020-000632).

Accepted 07 April 2020

Check for updates

(C) Author(s) (or their employer(s)) 2020. Re-use permitted under CC BY-NC. No commercial re-use. See rights and permissions. Published by BMJ.

For numbered affiliations see end of article.

Correspondence to Pr Nathalie Chaput; CHAPUT-GRAS.nathalie@ gustaveroussy.fr

\section{ABSTRACT}

Background As the immune system is compromised in patients with cancer, therapeutic strategies to stimulate immunity appear promising, to avoid relapse and increase long-term overall survival. Interleukin-15 (IL-15) has similar properties to IL-2, but does not cause activationinduced cell death nor activation and proliferation of regulatory T cells (Treg), which makes it a serious candidate for anticancer immunotherapy. However, IL-15 has a short half-life and high doses are needed to achieve responses. Designed to enhance its activity, receptorlinker-IL-15 (RLI) (S0-C101) is a fusion molecule of human IL-15 covalently linked to the human IL-15R $\alpha$ sushi+ domain currently assessed in a phase $\mathrm{I} / \mathrm{lb}$ clinical trial on patients with advanced/metastatic solid cancer

Methods We investigated the antimetastatic activity of RLI in a 4T1 mouse mammary carcinoma that spontaneously metastasizes and evaluated its immunomodulatory role in the metastatic lung microenvironment. We further characterized the proliferation, maturation and cytotoxic functions of natural killer (NK) cells in tumor-free mice treated with RLI. Finally, we explored the effect of RLI on human NK cells from healthy donors and patients with non-small cell lung cancer (NSCLC).

Results RLI treatment displayed antimetastatic properties in the 4T1 mouse model. By characterizing the lung microenvironment, we observed that RLI restored the balance between NK cells and neutrophils (CD11 b ${ }^{+}$ Ly6G ${ }^{\text {high }}$ Ly6 $\mathrm{C}^{\text {low }}$ ) that massively infiltrate lungs of $4 \mathrm{~T} 1$ tumor bearing mice. In addition, the ratio between NK cells and Treg was strongly increased by RLI treatment. Further pharmacodynamic studies in tumor-free mice revealed superior proliferative and cytotoxic functions on NK cells after RLI treatment compared with IL-15 alone. Characterization of the maturation stage of NK cells demonstrated that RLI favored accumulation of

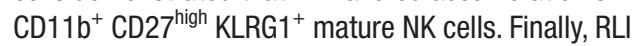
demonstrated potent immunostimulatory properties on human NK cells by inducing proliferation and activation of NK cells from healthy donors and enhancing cytotoxic responses to NKp30 crosslinking in NK cells from patients with NSCLC.

Conclusions Collectively, our work demonstrates superior activity of RLI compared with rhIL-15 in modulating and activating NK cells and provides additional evidences for a therapeutic strategy using RLI as antimetastatic molecule.

\section{BACKGROUND}

Interleukin-15 (IL-15) plays a pivotal role in innate and adaptive immunity. IL-15 activates immune cells by binding to the IL-15 receptor. This receptor is composed of three chains: IL-2/IL-15R $\beta$ (CD122); IL-2/IL-15R $\gamma$ c (CD132) chains and a high affinity-specific chain (IL-15R $\alpha$ ). Given that IL-2 and IL-15 receptors shared two chains, it is possible that these two cytokines exhibit similar activities. Indeed, in vitro data showed analogous activities between IL-2 and IL-15 in the stimulation of the proliferation and functions of natural killer (NK) and T cells, B cell costimulation, and chemoattraction of lymphocytes. ${ }^{12}$ However, in vivo results showed differences in properties between these two cytokines. IL-2 or IL-2R $\alpha$ knockout mice developed an autoimmune phenotype with an increase in activated $\mathrm{T}$ and $\mathrm{B}$ cells, while IL-15 or IL-15R $\alpha$ knockout mice displayed profound NK, NK-T, intraepithelial lymphocyte and memory $\mathrm{CD}^{+} \mathrm{T}$ cell deficits. ${ }^{34}$ Moreover, while IL-15 promotes memory T cell survival, IL-2 promotes activation-induced cell death (AICD) and proliferation/activation of Treg resulting in peripheral tolerance..$^{56}$

IL-2 is currently approved for clinical use in metastatic melanoma and metastatic renal cell carcinoma. However, IL-2 therapy in patients with cancer is difficult to manage due to its high toxicity, AICD of effector T cells and its ability to induce proliferation and activation of regulatory $T$ cells that can counteract its antitumor efficacy. ${ }^{7}$ In this regard, IL-15 has some advantages. In 2007, IL-15 was ranked one of the most promising immunotherapeutic agent with high potential to cure 
cancer. $^{8}$ As IL-15 is more stable when bound to its high affinity receptor IL-15R $\alpha$, an IL-15 superagonist (RLI for receptor-linker-IL-15) has been developed, composed of the $\mathrm{NH}(2)$-terminal (amino acids 1-77, sushi+) domain of the IL-15R $\alpha$ coupled via a linker to IL-15. ${ }^{9}$ This human fusion protein behaves like a potent superagonist of the IL-15R $\beta \gamma$ complex and increases the half-life of IL-15 by mimicking IL-15 transpresentation. ${ }^{10}$ RLI was shown to promote NK cell development and differentiation in human immune system (HIS) mice, ${ }^{11}$ to promote $\mathrm{T}$ cell reconstitution and T-cell-dependent antibody responses in HIS mice, ${ }^{12}$ to induce higher proliferation of effector memory $\mathrm{CD}^{+} \mathrm{T}$ cells in vitro compared with IL-7 in HIV positive patients ${ }^{13}$ and to synergize with anti-GD2 or anti-CD20 when targeted in the tumor in preclinical mouse models. ${ }^{14}{ }^{15}$ In addition, we showed that RLI can also increase the anti-tumor activity of anti-PD-1 antagonists in mouse models of colorectal cancer and promotes the proliferation and functions of $\mathrm{CD}^{+} \mathrm{T}$ cells in vivo, ${ }^{16}$ suggesting RLI is a promising immunotherapeutic candidate. In fact, safety and preliminary efficacy of RLI alone or in combination with pembrolizumab, a PD-1 antagonist, is currently assessed in a phase I/Ib clinical trial on patients with advanced/metastatic solid cancer (SC103).

The aim of this study was to investigate (1) the modulation of the metastatic microenvironment on RLI treatment in a physiological mouse metastatic model and (2) the role of RLI on mouse and human NK cells to determine its clinical relevance. We demonstrated its potent antimetastatic properties as monotherapy and strong proliferative and cytotoxic activities on human and mouse NK cells. Collectively, our work provides additional evidences of the therapeutic potential of the IL-15 superagonist RLI.

\section{Methods}

Mice and cell lines

$\mathrm{C} 57 \mathrm{Bl} / 6$ and $\mathrm{BALB} / \mathrm{c}$ mice were, respectively, purchased from Harlan Laboratories (Gannat, France) and Janvier Labs (Le Genest St Isle, France) and used between 8 and 12 weeks of age. Mouse mammary carcinoma 4T1 cell line (ATCC) was cultured in Roswell Park Memorial Institute 1640 (RPMI-1640) medium supplemented with $1 \mathrm{mM}$ sodium/pyruvate, $1 \mathrm{mM}$ of non-essential amino acids (NEAA), $100 \mathrm{IU} / \mathrm{mL}$ penicillin/streptomycin, $2 \mathrm{mM}$ L-Glutamine and 10\% fetal bovin serum (FBS, Life Technologies, Saint Aubin, France). All animal experiments were carried out in accordance with French and European laws and regulations and approved by the French Animal Experimentation Ethics Committee no 26.

\section{Healthy donors and patients}

Healthy donor blood samples were collected from the French blood bank (Etablissement Français du Sang (EFS); agreement number 12/EFS/079) and patient samples were collected from Gustave Roussy (Villejuif, France). All patients were suffering from advanced and inoperable non-small cell lung cancer (NSCLC) stage
IIIB/IV. Blood samples were drawn from patients after induction chemotherapy. Healthy donors and patients provided their written informed consent to participate in these studies prior to inclusion in the study.

\section{Reagents}

RLI was kindly provided by Cytune Pharma (Nantes, France). Recombinant human IL-15 (IL-15) was purchased from Cellgenix (Freiburg, Germany). All of these reagents were diluted in sterile phosphate buffered saline (PBS). Monoclonal antibodies used for flow cytometry analysis are described in online supplementary Additional file 1.

\section{Flow cytometry analysis}

Before staining, Fc receptors were blocked for $15 \mathrm{~min}$ at $4^{\circ} \mathrm{C}$ using anti-CD16/32 functional grade purified antibodies (eBioscience). Cells were incubated for $30 \mathrm{~min}$ at $4^{\circ} \mathrm{C}$ with antibodies for cell surface staining. For Ki67 and FoxP3 staining, cells were fixed and permeabilized after cell surface staining according to the FoxP3 kit protocol (eBioscience). LIVE/DEAD fixable aqua (Life Technologies) or Zombie Red (Ozyme) were used to stain dead cells. For intracellular cytokine staining, cells were fixed and permeabilized according to the Cytofix/Cytoperm protocol (BD biosciences). Samples were acquired on an 8-colors FACS Canto II cytometer (BD biosciences) or on 10-colors Gallios cytometer (Beckman Coulter, Villepinte, France). Analyses were performed using Kaluza software V.1.3 (Beckman Coulter).

Experiments with peripheral blood mononuclear cells from healthy donors

Proliferation assay. Peripheral blood mononuclear cells (PBMCs) were isolated on a Ficoll gradient. Then, $1.10^{6}$ fresh PBMC were incubated for $5 \mathrm{~min}$ at room temperature under agitation with a $2.5 \mu \mathrm{M}$ final concentration of carboxyfluorescein diacetate succinimidyl ester (CFSE, Sigma). The reaction was stopped with pure FBS and cells were washed three times in complete medium R10 (RPMI 1640 medium supplemented with $1 \mathrm{mM}$ sodium/ pyruvate, $1 \mathrm{mM}$ NEAA, $100 \mathrm{IU} / \mathrm{mL}$ penicillin/streptomycin, $2 \mathrm{mM}$ L-Glutamine and $10 \% \mathrm{FBS}$ ). PBMCs were seeded in a 96-well round bottom plate at $1.10^{6}$ cells $/ \mathrm{mL}$ in complete medium R10 and incubated at $37^{\circ} \mathrm{C}$ at indicated concentrations of RLI or $2.5 \mathrm{ng} / \mathrm{mL}$ IL-15 or $50 \mathrm{IU} /$ mL rhIL-2.

NK cell activating receptors detection. One million per $\mathrm{mL}$ of thawed PBMC were incubated for 2 days with medium (Cellgro, Cellgenix $+1 \%$ penicillin/streptomycin), IL-15 (10 ng/mL) or equimolar concentrations of RLI $(17.86 \mathrm{ng} / \mathrm{mL})$ in a 24-well plate. Then, the surface of cells was stained to detect human leukocyte antigen DR (HLA-DR) molecules and NK cell activating receptors among NK cells.

Human PBMC crosslink experiments

A 96-well Maxisorp plate was coated with anti-CD16 (clone 3G8, BioLegend), anti-NKp30 (clone 210847, 
$\mathrm{R} \& \mathrm{D}$ systems) or the respective mouse $\mathrm{IgG}_{1}$ and mouse IgG2a isotypes (at $2.5 \mu \mathrm{g} / \mathrm{mL}$ in $50 \mu \mathrm{L}$ of sterile PBS $1 \mathrm{X}$ ). Two millions per $\mathrm{mL}$ of thawed PBMC from patients with cancer were incubated for 18 hours with medium (Cellgro $+1 \%$ penicillin/streptomycin), IL-15 (10 ng/ $\mathrm{mL})$ or equimolar concentrations of RLI (17.86ng/ $\mathrm{mL})$. The next day, stimulated cells were incubated in an antibody-coated plate for 5 hours in the presence of antiCD107a, IL-2 (1000IU/mL) and brefeldin A. Then, the surface of cells was stained followed by an intracellular cytokine staining.

\section{In vivo bioactivity of $R L I$ in mice}

$\mathrm{C} 57 \mathrm{Bl} / 6$ naïve mice were injected intraperitoneally (i.p) with $100 \mu \mathrm{L}$ of PBS, IL-15 (1.2 $\mu \mathrm{g} /$ mouse) or equimolar dose of RLI ( $2 \mu \mathrm{g} /$ mouse) on day (D) 0 and D3. Mice were sacrificed on $\mathrm{D} 4$ and their organs were harvested for flow cytometry analyzes and ex vivo experiments.

\section{Metastatic experiments}

Fifty thousand $4 \mathrm{~T} 1$ tumor cells were inoculated in the mammary fat pad $\left(n^{\circ} 4\right)$ of BALB/c mice. Mice received i.p injections of RLI ( $2 \mu \mathrm{g} /$ mouse), IL-15 (1.2 $\mu \mathrm{g} /$ mouse) or control PBS four times a week from day 7 to day 24 . Tumor growth was followed up three times a week by measuring the length and width and was calculated as follows: size $\left(\mathrm{mm}^{2}\right)=$ length $\mathrm{x}$ width. Mice were euthanized when the tumor size was $\geq 300 \mathrm{~mm}^{2}$ or boundary points were reached according to the French and European laws and regulations for the use of mice for scientific purposes. To determine lung metastases, mice were sacrificed on day 28 and $1 \mathrm{~mL}$ of India Ink (15\%) was injected in the trachea. Lungs were removed and washed in PBS. Lobes were separated from bronchus and trachea and stored in Feket solution $(70 \%$ ethanol $(300 \mathrm{~mL}) / 37 \%$ formaldehyde $(30 \mathrm{~mL}) /$ cold acetic acid $(5 \mathrm{~mL}))$ for at least one night. Blind enumeration of lung metastases was then realized. Metastases were discriminated according the size and a score was attributed for each size (very small $(v)$ : score $=1$, small $(w)$ : score $=2$, medium $(x)$ : score $=6$, large $(y)$ : score $=12$, very large $(z)$ : score $=24)$. A total score for each mouse was calculated as follow: $(v \times 1)+(w \times 2)+$ $(x \times 6)+(y \times 12)+(z \times 24)$ where $v, w, x, y$ and $z$ were the number of metastases according the size. For flow cytometry analyses, mice were sacrificed on day 17 and lungs were dissociated as described below.

Mouse single cell preparation from spleen, lymph node, lung and bone marrow

Spleen and lymph node (LN): Single cells were obtained after mechanical disruption and red blood cells were lysed using ammonium-chlorure-potassium (ACK) lysing buffer (spleen). BM: bone marrow cells were isolated from the tibia and femur of the right leg by flushing with RPMI medium. Then red blood cells were lysed. Lung: Red blood cells were removed by flushing $10 \mathrm{~mL}$ of PBS in the right ventricle. Lungs were harvested and lobes dissociated. Lobes were placed in a $\mathrm{C}$ tube (Miltenyi,
Paris, France) containing digesting buffer (RPMI, $50 \mu \mathrm{g} /$ $\mathrm{mL}$ Liberase TM (Roche), $80 \mathrm{IU} / \mathrm{mL}$ DNase I (Calbiochem)). Then, lungs were mechanically dissociated using the GentleMACS dissociator (Miltenyi) according to the manufacturer's protocol.

\section{Mouse NK cell cytotoxicity assay}

An in vitro cytotoxicity assay was performed using the lactic acid dehydrogenase (LDH) cytotoxicity kit (Roche, Meylan, France) according to the manufacturer's protocol. Briefly, NK cells were purified from splenocytes using the NK cell enrichment kit II (Miltenyi) and cocultured with YAC-1 mouse tumor cells. Twenty thousand YAC-1 cells were seeded in 96-well v-bottom plates with different amounts of NK cells. After 4 hours of coculture, supernatants were removed and LDH measured. The percentage of cytotoxicity was calculated as follows: [(Experimental - Effector spontaneous - Target spontaneous) / (Target maximum - Target spontaneous) $\times 100$ ] .

\section{Intracellular cytokine assay in mouse splenocytes}

Splenocytes were seeded in a 6 -well plate at $2.10^{6}$ cells/ $\mathrm{mL}$ in complete medium R10 with phorbol myristate acetate (PMA) $(5 \mathrm{ng} / \mathrm{mL})$, ionomycin $(500 \mathrm{ng} / \mathrm{mL})$ and brefeldin A $(3 \mu \mathrm{g} / \mathrm{mL})$ for 4 hours. Then, the surface of cells was stained followed by intracellular cytokine staining.

\section{Microarray assay}

Microarray analyses of the CD45 negative-cell fraction directly sorted from the primary tumor and lungs on day 14 (before metastases implantation, no metastases detectable by conventional techniques) after two injections of PBS or RLI in tumor-bearing and non-tumor-bearing mice. Single cells from lung and tumors were sorted with a FACSAria III cell sorter (BD Biosciences). CD45 Dapi ${ }^{-}$ cell fractions were immediately centrifuged and pellets were frozen. RNA extractions and hybridizations were performed by the Microarray service of Miltenyi Biotech. Briefly, RNA was isolated using standard RNA extraction protocols (NucleoSpin RNA II, Macherey-Nagel). The quality of RNA samples was checked via the Agilent 2100 Bioanalyzer platform (Agilent Technologies) and the RNA Integrity Number (RIN) was generated. RIN $>6$ means that the quality of the RNA is sufficient for gene expression profiling. RNAs have RIN values between 7.1 and 8.1 for lung samples and 9.3 and 9.9 for tumor samples. Then, RNA samples were amplified and labeled with Cy-3 using the Agilent Low Imput Quick Amp Labeling kit (Agilent Technologies). Yields of cRNA and dye-incorporation rate were measured with ND-1000 Spectrophotometer (NanoDrop Technologies). Finally, the hybridization procedure was performed according to the Agilent 60-mer oligo microarray processing protocol using the Agilent Gene Expression Hybridization kit (Agilent Technologies). Fluorescence signals of the hybridized Agilent Microarrays were detected using the Agilent's Microarray Scanner System (Agilent technologies). 


\section{Microarray data analysis}

Image analysis. The Agilent Feature Extraction Software was used to read out and process the microarray image files. The software determines feature intensities (including background subtraction), rejects outliers and calculates statistical confidences.

Data analysis. For each microarray, raw data file were processed using R bioconductor package as well as homemade R script. Raw data file were first imported into R. Controls probes were systematically removed, and flagged probes (gIsSaturated, gIsFeatpopnOL, gIsFeatNonUnifOL) were set to NA. We used 'ArrayQualityMetrics' package to evaluate the quality of each transcriptomic profil. Normalization was performed by a quantile normalization on Cy3 channel (gMedianSignal). The mean of each replicated probes were computed to summarize the data at transcript level. Missing values were inferred using KNN-algorithm from the package 'impute' from $\mathrm{R}$ bioconductor.

PCA. PCA was built using 'prcomp' function from R with the normalized values of the transcriptomic profil of all samples.

\section{Statistical analyses}

Statistical analyzes were performed using Prism 6.0 (GraphPad) Software. The Kruskall-Wallis test was used to compare more than two independent groups and completed with Dunn's non-parametric multiple comparisons tests. On ordinary one-way ANOVA and HolmSidak's multiple comparisons test is processed when Gaussian distribution is assumed. The Mann-Whitney test was performed to compare two unmatched groups. An ordinary two-way ANOVA, followed by Bonferroni multiple comparisons tests, were performed for the cytotoxicity assay. The Friedman test was used to compare more than two matched groups. Significant $p$ values were annotated as follows $* \mathrm{p}<0.05, * * \mathrm{p}<0.01, * * * \mathrm{p}<0.001$, $* * * * \mathrm{p}<0.0001$.

\section{Results}

RLI treatment reduces spontaneous lung metastases in mice

The in vivo metastatic process is complex and requires communications between primary tumor and metastatic niche. Tumor cells acquire invasive phenotype at the primary site to reach the circulation. Then, rare tumor cells that survive in circulation can invade distant sites educated to receive these metastases. ${ }^{17}$ We, thus, decided to investigate the effect of RLI in a physiological model of metastasis: the 4T1 mammary carcinoma model in mice. 4T1 mammary carcinoma is an orthotopic transplantable tumor cell line highly tumorigenic, invasive and, unlike most tumor models, can spontaneously metastasize from the primary tumor in the mammary gland to multiple distant sites including LN, blood, liver, lung, brain, and bone that mimics very closely human breast cancer. ${ }^{18}$ First, we investigated the anti-metastatic activity of RLI by treating mice 7 days after tumor implantation (tumor size $\sim 15 \mathrm{~mm}^{2}$ ) with PBS, RLI or IL-15 as depicted in figure 1A. We could detect lung metastases on day 21, but we could not exclude the presence of micrometastases the day of the initiation of the treatment. On day 28 , after 3 weeks of treatment, mice were euthanized and pulmonary metastases were enumerated after India ink coloration of lungs. We applied a score according the size of metastases to include this parameter in our analysis. Despite a trend observed with IL-15, only RLI induced a significant reduction of the score of lung metastases (figure 1B). Previous studies have reported a correlation between tumor size and metastasis in this model. ${ }^{19}$ Here, we found the same positive correlation with $\mathrm{r}=0.73$ in PBS treated mice (figure 1C). RLI treatment however did not affect the growth of the primary tumor and no correlation was noted $(\mathrm{r}=0.38)$, suggesting that the decrease in lung metastases was an anti-metastatic effect resulting from these treatments and not a consequence of a reduced growth of the primary tumor (figure $1 \mathrm{C}, \mathrm{D}$ ). To further investigate the effect of the IL-15 trans-signaling on the metastatic colonization, we discriminated metastases according the size. The number of small metastases was the same between all groups (figure 1E). However, medium and especially large metastases decreased with RLI treatment suggesting a diminution of the growth of implanted metastases. Finally, we examined the number of metastatic events (all metastases regardless of size). Despite a trend observed, no significant differences were reached after RLI or IL-15 treatment (figure 1F).

Collectively these data demonstrate the antimetastatic properties of the IL-15 superagonist RLI and suggest RLI might prevent the growth of lung metastases rather than the metastatic colonization.

RLI modifies the balance between NK cells and regulatory T cells and neutrophils in the pulmonary metastatic niche

To decipher the antimetastatic properties of RLI, we explored the cellular composition of lungs after treatment. No expression of IL-15 receptor chains could be detected on $4 \mathrm{~T} 1$ tumor cells ruling out a possible direct cytotoxic effect of RLI. In addition, microarray analysis demonstrated that RLI did not impact the CD45 negative fraction of the metastatic niche including stromal cells and primary tumor cells (online supplementary additional file 2). Microarray analysis clearly showed that the primary tumor has an impact on the pulmonary metastatic niche while absolutely no difference could be observed between RLI- and PBS-treated mice (online supplementary additional file 2A). These data argue for an indirect antimetastatic activity of RLI treatment through the modulation of the CD45 positive hematopoietic cell fraction in the metastatic niche. We thus analyzed immune infiltration in the lung of 4T1-bearing mice. We first considered the cytotoxic effector cells which could have restrained the growth of metastatic tumor cells, $\mathrm{CD} 8^{+} \mathrm{T}$ cells and NK cells. Surprisingly, RLI did not affect the frequency or the absolute number of $\mathrm{CD}^{+} \mathrm{T}$ cells infiltrating the lung (online supplementary additional file 2B). To note, IL-15 alone induced significant increase of both frequency and 

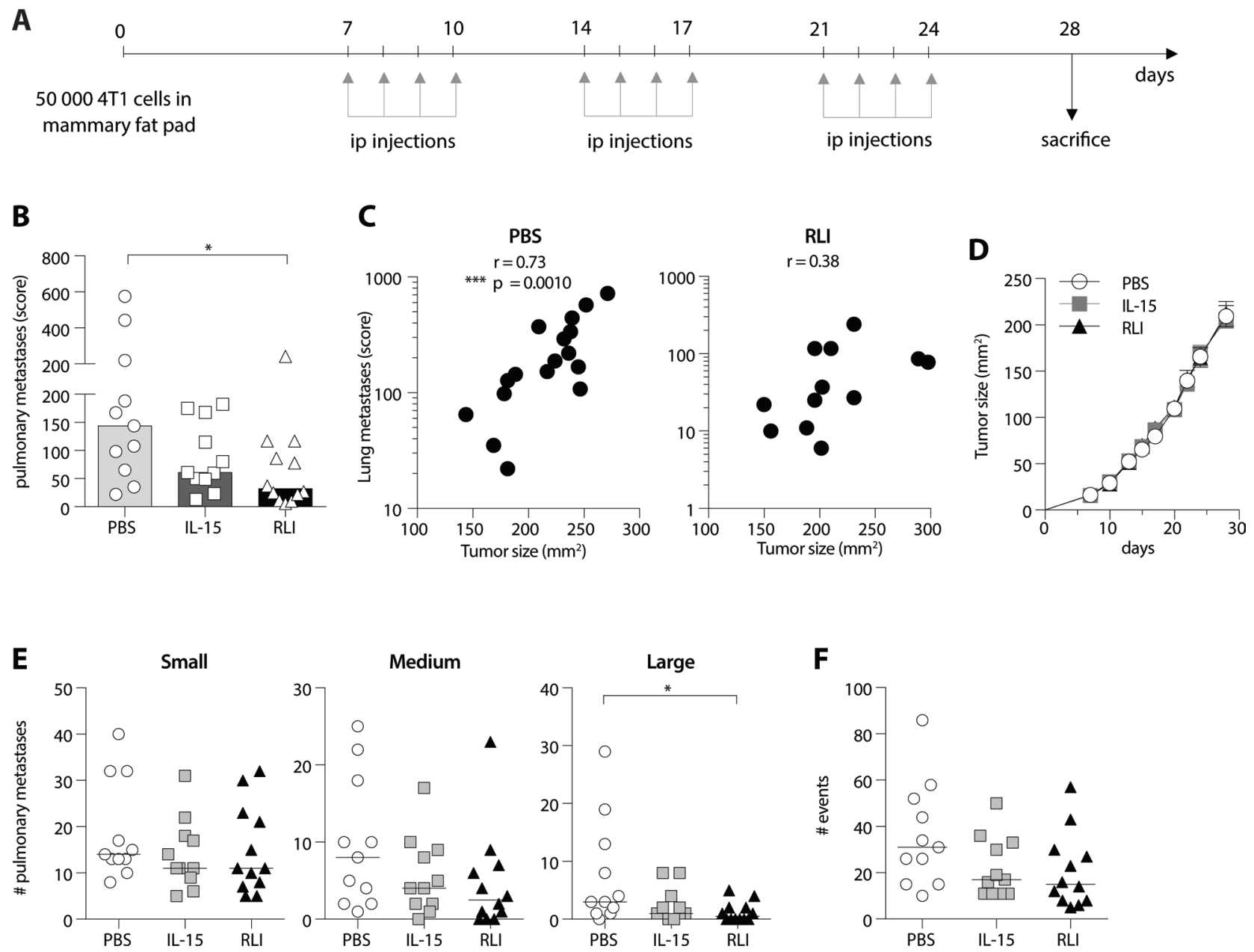

Figure 1 Antimetastatic activity of RLI in a spontaneous tumor metastasis mouse model. 4T1 tumor-bearing mice were treated four times a week with PBS, IL-15 or RLI. Mice were sacrificed on day 28 and lung metastases were counted. (A) Schematic protocol of treatments. (B) Metastatic score assigned for each mouse as described in the Methods section. (C) Correlation between lung metastases and tumor size in PBS-treated (left) and RLI-treated group (right). (D) Graphs show mean values \pm SEM of tumor sizes. (E) The distribution of metastases according the size is reported. Graphs show median values and each point represent a mouse. $(F)$ The number of metastatic events independently of the size is presented. Statistical significance was determined using the Kruskal-Wallis test and Dunn's multiple comparison test. ${ }^{*} \mathrm{P}<0.05,{ }^{\star \star \star} \mathrm{P}<0.001$. IL-15, interleukin-15; ip, intraperitoneally; RLI, receptor-linker-IL-15.

number of $\mathrm{CD}^{+} \mathrm{T}$ cells, although a trend but not significant antimetastatic activity was observed. In contrast, RLI markedly induced the proliferation and accumulation of NK cells in lungs of 4T1-bearing mice whereas a lower increase of NK cells could be observed with IL-15 (figure 2A). IL-15 treatment led to the proliferation of NK cells in the lung but this proliferation remained inferior to that observed with RLI. In lungs from tumor-free (naïve) or tumor-bearing mice, most NK cells $(\sim 90 \%)$ exhibit a mature phenotype $\mathrm{CD}_{11 \mathrm{~b}^{+}} \mathrm{CD} 27^{-}$(online supplementary additional file 2C). Interestingly, mice treated with RLI dramatically increased the expression of the killer cell lectin-like receptor G1 (KLRG1) molecules on NK cells with a limited upregulation observed after IL-15 treatment (figure 2B-C), suggesting that RLI promotes a terminally differentiated phenotype.

Naive mice have been used as controls to verify the impact of the tumor colonization on lung infiltrate. While the percentage drastically decreased, no difference in absolute number of NK cells (and $\mathrm{CD}^{+} \mathrm{T}$ lymphocytes) between naïve and PBS-treated tumor bearing mice (figure $2 \mathrm{~A}$ and online supplementary Additional file 2B) could be depicted suggesting a massive infiltration of another cell type. Emerging evidences indicate a role for secreted factors from primary tumor or circulating tumor cells to convert distant sites and prepare arrival of tumor cells in the so called 'pre-metastatic niche'. BM-derived cells including $\mathrm{CD} 11 \mathrm{~b}^{+}$myeloid cells and regulatory $\mathrm{T}$ cells (Treg), are recruited to shape this niche and allow adhesion, invasion and colonization of metastatic cells. ${ }^{1720}$ Accordingly, we have investigated whether RLI could modulate CD11 $\mathrm{b}^{+}$myeloid and Treg cells favoring this pro-tumor environment. The proportion of lung Treg cells was diminished in all groups of tumor bearingmice when compared with naïve mice. However, absolute numbers of Treg cells were comparable in all studied groups except with IL-15 treatment where the number of Treg cells was significantly increased in comparison to 
A

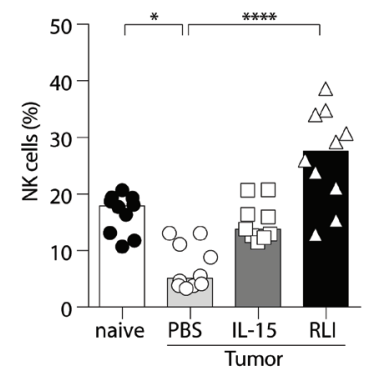

B
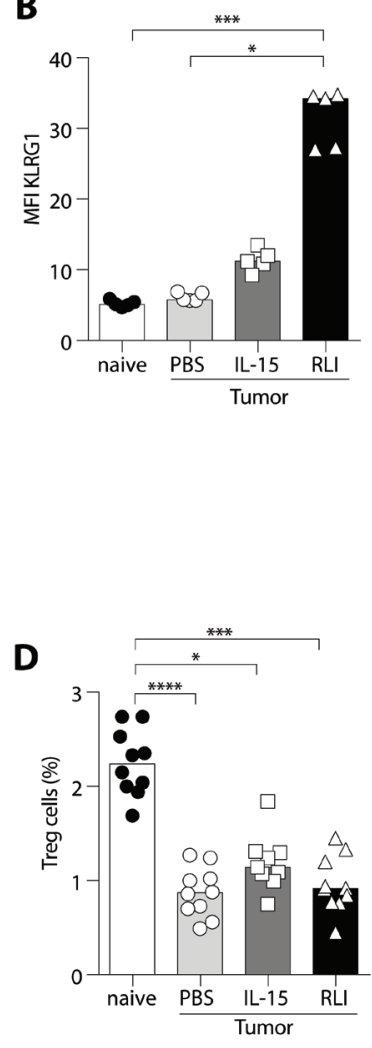

$\mathbf{F}$

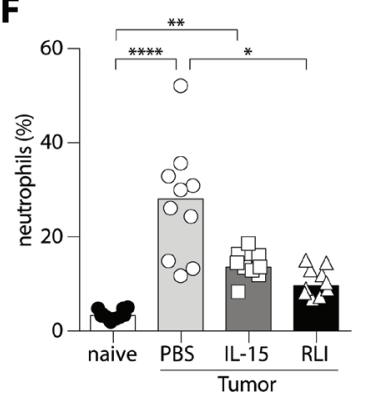

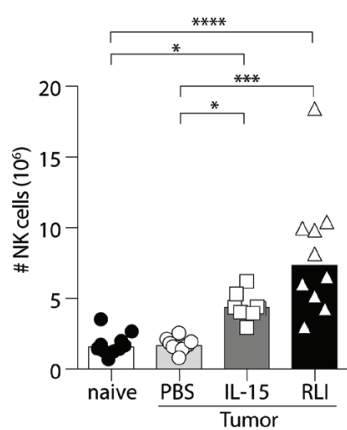

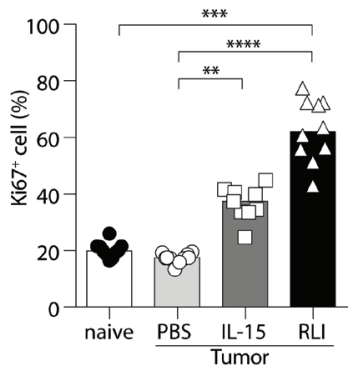

C
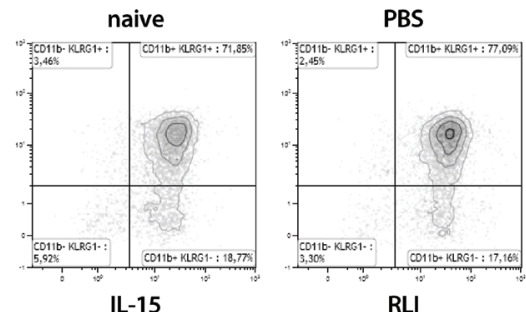

RLI
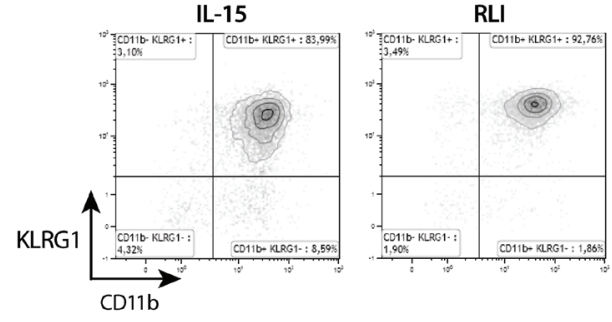

Figure 2 RLI promoted the proliferation and maturation of NK cells in metastatic lungs and restored the NK/neutrophils ratio to normal without affecting Treg cells. 4T1 tumor-bearing mice were treated four times a week with PBS, IL-15 or RLI and euthanized on day 17 to collect lungs. Mice without tumor inoculation were also included in this experiment (naïve). Analysis of NK cell infiltrate in lung of treated mice is depicted in (A) with the percentage of NK cells $\left(\mathrm{CD} 3^{-} \mathrm{NKp} 46^{+}\right)$among $\mathrm{CD} 45^{+}$cells in lungs (left panel), absolute numbers of NK cells (middle panel) and the proliferation of NK cells defined by Ki6 ${ }^{+}$cells (right panel) ( $n=8-10$ mice). (B) Geometric mean of fluorescence intensity (MFI) of KLRG1 in NK cells is shown ( $n=5$ ) along with (C) representative dot plots of the expression of CD11b and KLRG1 among NK cells. (D) Treg infiltrate in lung (CD3 ${ }^{+} \mathrm{CD}^{+}{ }^{+}$Foxp3 $^{+}$) with the percentage among $\mathrm{CD} 45^{+}$cells (left panel) and absolute numbers (right panel). (E) NK to Treg cells ratio is presented. (F) Neutrophil infiltrate (Lin ${ }^{-}\left(\mathrm{CD} 3, \mathrm{CD} 19, \mathrm{NKp46)}\right.$ CD11b ${ }^{\text {high }} \mathrm{Ly}_{6 \mathrm{G}^{+}} \mathrm{Ly}_{6 \mathrm{C}^{\mathrm{low}}}$ ) with percentage among CD45 ${ }^{+}$cells (left panel) and absolute numbers (right panel). (G) NK cells/neutrophils ratio. Data pooled from one (B) or two independent experiments (A, D-G) are presented. Statistical significance was determined using the Kruskal-Wallis test and Dunn's multiple comparison test. ${ }^{\star} \mathrm{P}<0.05,{ }^{\star \star} \mathrm{P}<0.01,{ }^{* \star *} \mathrm{P}<0.001,{ }^{* \star \star \star} \mathrm{P}<0.0001$. IL-15, interleukin-15; KLRG1, killer cell lectin-like receptor G1; NK, natural killer; RLI, receptor-linker-IL-15. 
naïve mice (figure 2D). Nevertheless, the percentage of proliferative Treg cells, according Ki67 expression, was unchanged between PBS, IL-15 and RLI-treated mice (online supplementary additional file 2), suggesting a slight increase of recruitment of these cells after IL-15 treatment rather a proliferative activity. Since NK cells were increased after RLI treatment it is not surprizing to observe an increase of the NK/Treg ratio in the lung of mice treated with RLI and only moderately with IL-15 (figure 2E). As Treg cells did not appear to be notably modulated by IL-15-based treatments in the pulmonary metastatic niche in this model, we analyzed $\mathrm{CD} 11 \mathrm{~b}^{+}$ myeloid infiltrate in the lung (online supplementary additional file 2E). The major part of these myeloid cells is formed by neutrophils (CD11b ${ }^{+} \mathrm{Ly}_{6} \mathrm{G}^{+} \mathrm{Ly} \mathrm{C}^{\text {low }}$ cells). Whereas few neutrophils are present in the lung of naive mice, the percentage and number of these cells are deeply increased in tumor-bearing mice $(\mathrm{p}<0.0001)$. Unexpectedly, the neutrophil infiltrate (frequency and absolute number) was reduced after IL-15-based treatments (figure 2F). Moreover, these IL-15-based treatments modified the $\mathrm{NK} /$ neutrophil ratio with the strongest increase compared with untreated mice observed with RLI treatment $(\mathrm{p}<0.001)$. Interestingly, this $\mathrm{NK} /$ neutrophil ratio almost returned to what was observed in naive mice (figure 2G). These data suggest that RLI modulates the pulmonary infiltrate by modifying the balance between effector cells and immune regulators.

RLI elicits accumulation, proliferation and maturation of mouse NK cells with increased effector functions

We have demonstrated an antimetastatic activity of the superagonist RLI along with the accumulation, proliferation and maturation of NK cells despite an immunosuppressive metastatic microenvironment. To further dissect its mechanism of action on NK cells, we investigated the proliferation and maturation of these cells in lymphoid and non-lymphoid organs in absence of tumor. Administration of RLI on day 0 and day 3 resulted in significant increases of the percentage and absolute number of NK cells in the spleen on day 4 (figure 3A, left and middle). Although equimolar dose of IL-15 increased the percentage of NK cells, we did not observe a significant increase of their absolute numbers. Moreover, RLI was 1.7fold more effective than IL-15 to induce the proliferation of NK cells (figure 3A, right and figure 3B). Other scrutinized organs demonstrated that RLI could favor accumulation of NK cells in BM and lung and induces significant proliferation of NK cells in all compartments studied (online supplementary additional file 3A,B). Next, we evaluated the role of RLI in promoting the maturation of NK cells. We have shown earlier that RLI can induce the expression of KLRG1 on NK cells but all lung NK cells are fully mature. To investigate its role on the different steps of maturation according CD11b and CD27 expression, we examined the lymphoid organs (spleen, LN and $\mathrm{BM})$. We observed variations in the percentage and absolute numbers of the intermediate mature stage NK cells
$\left(\mathrm{CD} 11 \mathrm{~b}^{+} \mathrm{CD} 27^{\text {high }}\right)$ between untreated and RLI-treated mice in spleen $(\mathrm{p}<0.01)$ and $\mathrm{BM}(\mathrm{p}<0.001)$ and a slight change in LN, suggesting activation and/or selective expansion and mobilization of these cells (figure 3C,D and online supplementary additional file $4 \mathrm{~A}$ ). In respect to the fully mature stage of NK cells $\left(\mathrm{CD} 11 \mathrm{~b}^{+} \mathrm{CD} 27^{\text {low }}\right)$, the percentage of these cells was reduced but we could not observe a significant difference in absolute numbers in the spleen (figure 3C). Although the same trend was observed with IL-15, no significant difference in absolute numbers was revealed. It is noteworthy that the $\mathrm{CD}_{11} \mathrm{~b}^{+}$ CD27 $7^{\text {high }}$ compartment had returned to normal when the mice were sacrificed 3 days after the last injection demonstrating a transient and reversible effect of RLI (data not shown). Finally, we inspected the expression of KLRG1 in all scrutinized organs after IL-15-based treatments. Unlike IL-15, only RLI significantly induced the accumulation of KLRG1 ${ }^{+} \mathrm{CD} 11 \mathrm{~b}^{+} \mathrm{NK}$ cells in the spleen (figure 3D,E). Despite a preferential expansion of intermediate mature NK cells, RLI induced KLRG1 expression on both mature $\mathrm{CD} 11 \mathrm{~b}^{+} \mathrm{CD} 27^{\text {high }}$ and $\mathrm{CD} 11 \mathrm{~b}^{+} \mathrm{CD} 27^{\text {low }}$ subsets, basal expression of KLRG1 being higher on fully mature $\mathrm{CD} 11 \mathrm{~b}^{+} \mathrm{CD} 27^{\text {low }} \mathrm{NK}$ cells. RLI increased drastically KLRG1 on $\mathrm{CD}_{11} \mathrm{~b}^{+} \mathrm{CD} 27^{\text {high }}$ NK cells thus reaching a proportion closed to that observed on $\mathrm{CD}_{11} \mathrm{~b}^{+}$ CD2 $7^{\text {low }}$ NK cells whereas IL-15 failed to do so on either subsets (online supplementary additional file 4B,C). This increased expression of KLRG1 on NK cells after RLI treatment was observed in all compartments studied (online supplementary additional file 4D).

Characteristics of senescence or end-stage during the contraction phase of immune response were reported about $\mathrm{KLRG}^{+}$mature NK cells (reduced proliferative capacity and effector functions, increased apoptosis). ${ }^{21} 22$ To determine whether RLI could induce such a functional defect in NK cells, we assessed NK cell functions in PBS, IL-15 and RLI-treated mice. Purified splenic NK cells from RLI-treated mice displayed the strongest capacities to lyse YAC-1 cells with a 2.1-fold change at the highest effectortarget ratio compared with IL-15-treated (figure 3F). In addition, splenocytes from RLI-treated mice exhibited higher IFN $\gamma$ secretion in NK cells (figure 3G).

Altogether, these data further support the immunomodulatory property of RLI on mouse NK cells by promoting their proliferation, maturation and cytotoxic functions with a constant superior activity observed in comparison to IL-15 alone.

RLI induces proliferation and upregulation of activating receptors of primary human NK cells

To study the capacity of RLI to stimulate and activate human NK cells, we first carried out a set of experiments on PBMC from healthy donors. We cultured fresh PBMC with escalating doses of RLI or medium alone and measured the proliferation at different time points using CFSE-dilutions assay by flow cytometry. RLI induced significant proliferation on days 4-5 of culture compared with that observed in medium (figure $4 \mathrm{~A}$ ). The minimum 

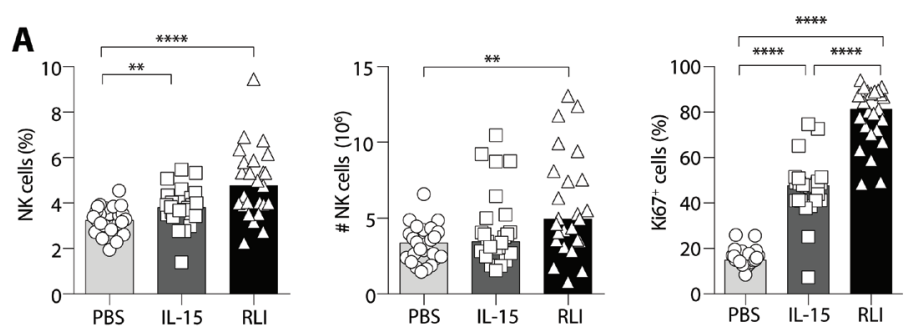

B

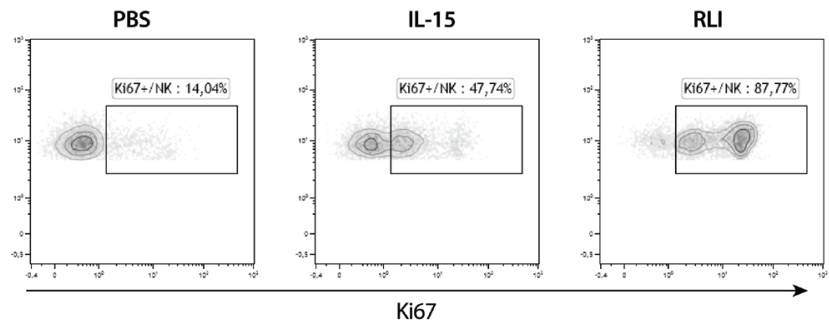

C CD11b-CD27 $7^{\text {high }}$ cells

CD11b+CD27 ${ }^{\text {high }}$ cells

CD11b+CD27 low cells
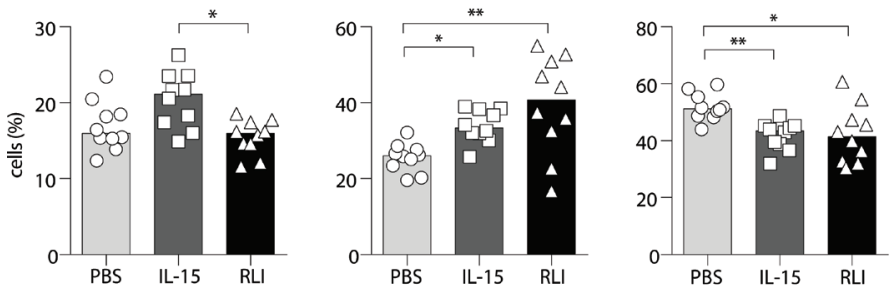

E

CD11b+KLRG1+ cells
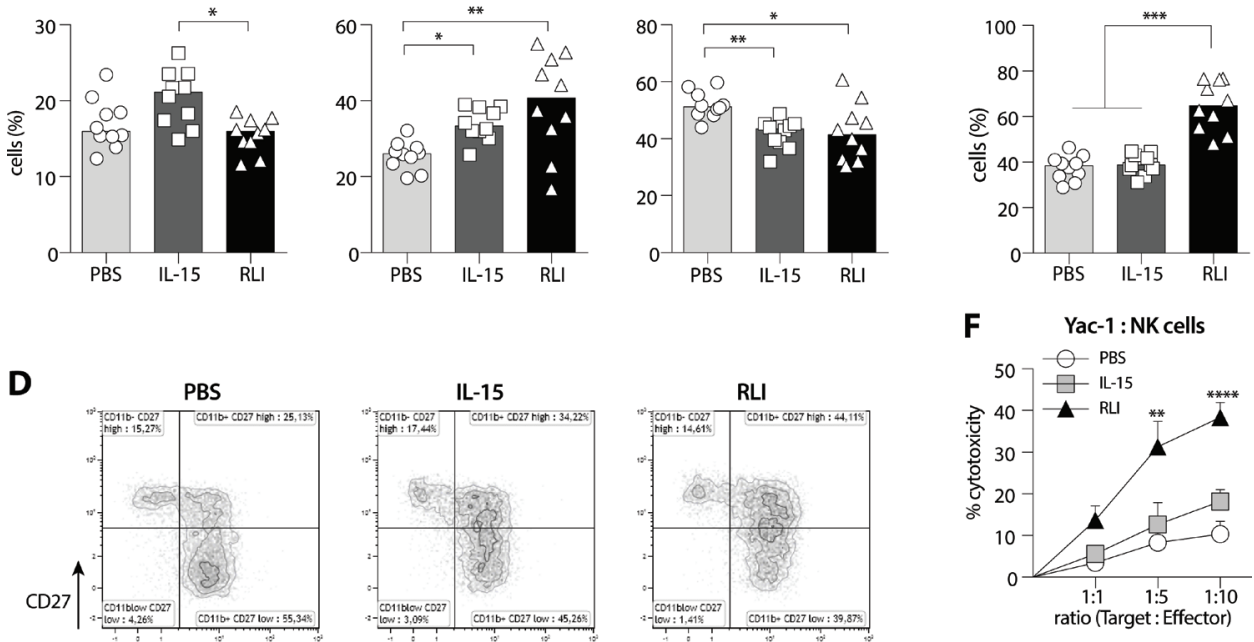

$\mathbf{F}$

Figure $3 \mathrm{RLI}$ induced accumulation, proliferation, maturation and cytotoxic function of NK cells in tumor-free mice. Immunomodulatory activity of RLI on NK cells was further investigated on tumor-free mice the day following the second dose (day 4). (A) Percentage of NK cells among viable cells in the spleen (left), absolute number (middle) and percentage of proliferative cells $\left(\mathrm{Ki} 67^{+}\right)$among NK cells (right) is exhibited for all three treatments PBS, IL-15 and RLI. Median values are presented and data from five independent experiments are pooled $(n=25)$. (B) Representative dot plots of Ki67 expression in NK cells. (C) Immature and mature subsets were analyzed in the spleen by flow cytometry according CD11b/CD27 expression after PBS, IL-15 or RLI treatments and the frequencies (top) and absolute numbers (bottom) are depicted. Median values are presented and data from two independent experiments are pooled $(n=10)$. (D) Representative dot plots of CD11b/CD27 (top) and CD11b/KLRG1 (bottom) subsets analyzed among NK cells. (E) Frequencies (top) and absolute numbers (bottom) of CD11 b $\mathrm{KLRG}_{1}{ }^{+}$cells among NK cells in spleen. Median values are presented and data from two independent experiments are pooled $(n=10)$. ( $F-G)$ Cytotoxic functions of NK cells from tumor-free mice after PBS, IL-15 or RLI treatment were analyzed ex vivo. (F) Enriched splenic NK cells were cocultured with YAC-1 cells at indicated ratios and LDH release was measured. The graph represents the mean \pm SEM of four independent experiments (two independent experiments for ratio 1:5). (G) Splenocytes were stimulated for 4 hours with the leukocyte activation cocktail (PMA/ionomycin) and brefeldin A. Intracellular staining of IFN $\gamma$ was performed and analyzed by flow cytometry. Data from three independent experiments $(n=15)$ are pooled and median values are presented. (A) Ordinary one-way ANOVA and Tukey's multiple comparisons test. (C-E, G) Kruskal-Wallis test and Dunn's multiple comparisons test. (F) Ordinary two-way ANOVA and Bonferroni's multiple comparisons test. ${ }^{*} \mathrm{P}<0.05$, ${ }^{* *} \mathrm{P}<0.01$, ${ }^{* * \star} \mathrm{P}<0.001,{ }^{* * \star *} \mathrm{P}<0.0001$. ANOVA, analysis of variance; IFN $\gamma$, interferon- $\gamma$; IL-15, interleukin-15; KLRG1, killer cell lectin-like receptor G1; NK, natural killer; RLI, receptor-linker-IL-15. 
A

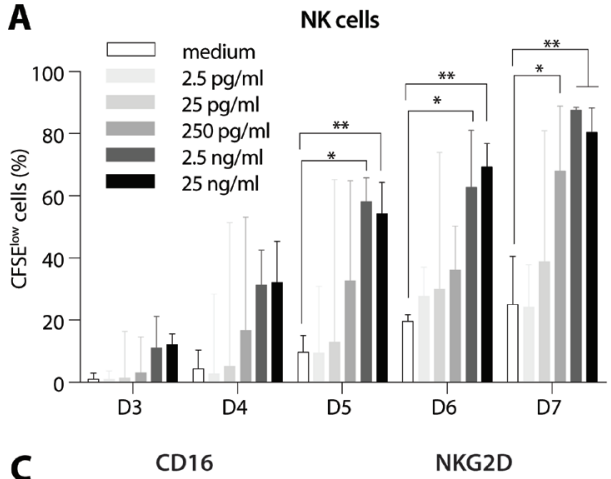

B
NK cells
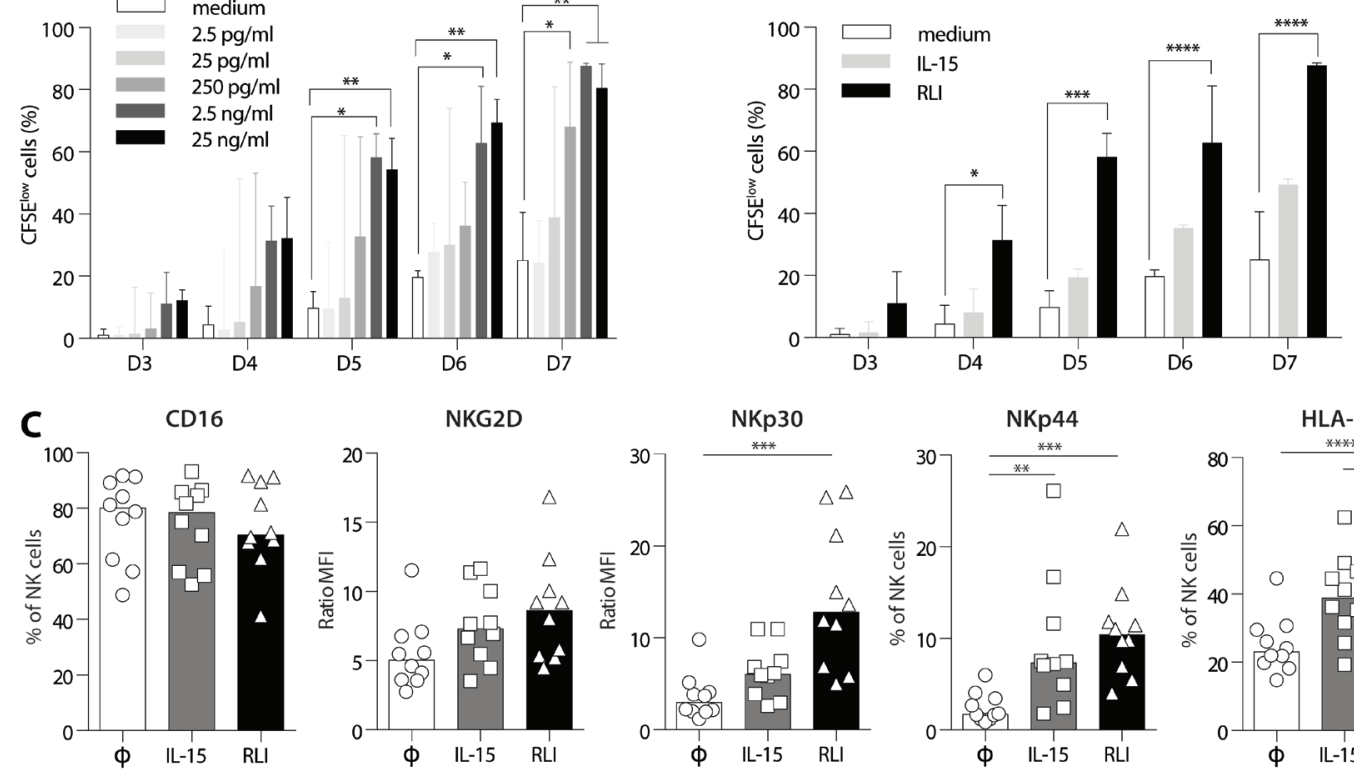

D3
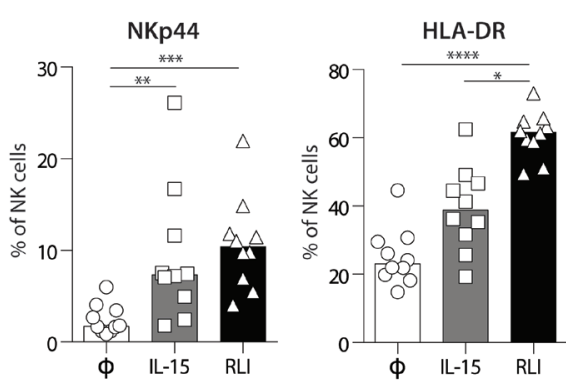

D
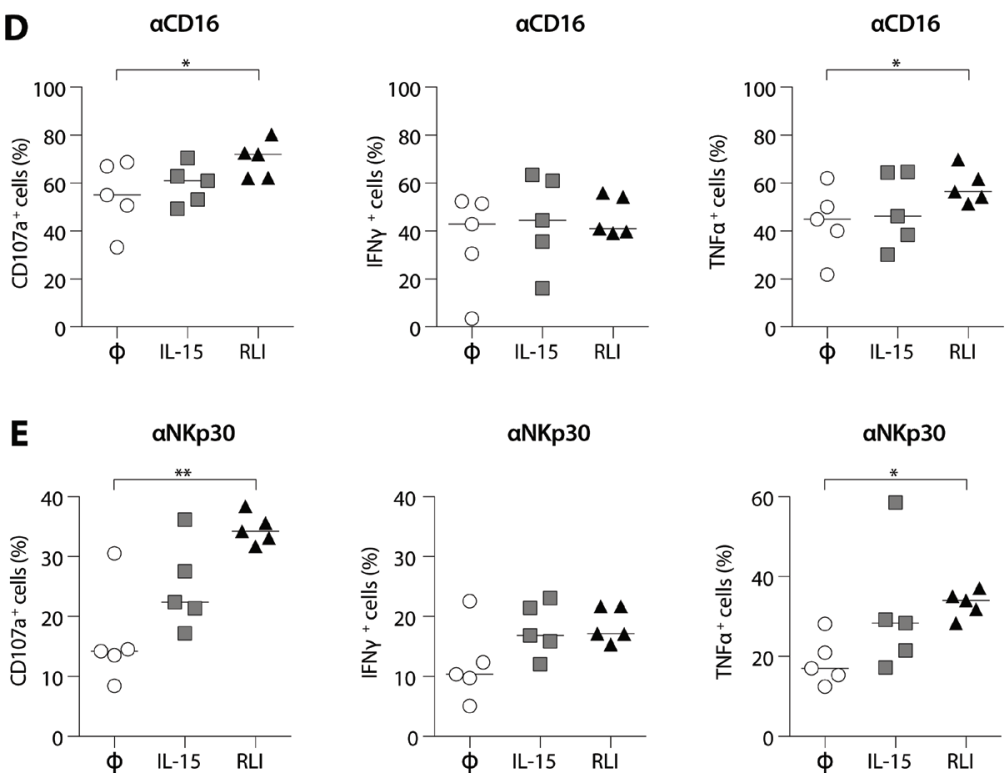

Figure 4 RLI induced the proliferation and increased functions of human NK cells. Freshly collected PBMC from healthy donors were cultivated with RLI for 3 to 7 days and the proliferation of NK cells (CD3- CD56 ${ }^{+}$) analyzed by flow cytometry following the CFSE dilutions. (A) PBMC were incubated with medium alone (white box) or escalating doses of RLI (shades of gray boxes) (2.5; 25; $250 \mathrm{pg} / \mathrm{mL} ; 2.5$ and $25 \mathrm{ng} / \mathrm{mL}$ ). (B) PBMC were incubated with medium alone (white box), $2.5 \mathrm{ng} / \mathrm{mL}$ of IL-15 (light gray) or $2.5 \mathrm{ng} / \mathrm{mL}$ of RLI (black). Graphs represent the median with IQR. Data from three independent experiments were pooled. (C-E) PBMC from healthy donors (C) or patients with advanced NSCLC (D, E) were treated overnight (D, E) or for 2 days (C) with medium alone $(\Phi)$, IL-15 or RLI. (C) Cell surface expression of CD16, NKG2D, NKp30, NKp44 and HLA-DR molecules among NK cells are shown $(n=10)$. Ratio MFI represents the geometric mean of fluorescence intensity reported on the isotype control. (D, E) Expressions of CD107a, IFN $\gamma$ and TNF $\alpha$ among NK cells (CD3- CD56 ${ }^{+}$viable cells) after CD16 (D) or NKp30 (E) cross-linking are presented $(n=5)$. (A, B) 2-way ANOVA with matched values and Dunnett's multiple comparisons test. medium was used as a reference. (C) Kruskal-Wallis test and Dunn's multiple comparisons test. (D) Friedman test and Dunn's multiple comparisons test. ${ }^{*} \mathrm{P}<0.05,{ }^{* *} \mathrm{P}<0.01,{ }^{* * *} \mathrm{P}<0.001$, ${ }^{* * *} \mathrm{P}<0.0001$. ANOVA, analysis of variance; IFN $\gamma$, interferon- $\gamma$, IL-15, interleukin-15; NK, natural killer; PBMC, peripheral blood mononuclear cells; RLI, receptor-linker-IL-15; TNF $\alpha$, tumor necrosis factor $\alpha$.

concentration required to observe a statistically significant effect was $2.5 \mathrm{ng} / \mathrm{mL}$ (figure $4 \mathrm{~A}$ ). We next compared the ability of RLI $(2.5 \mathrm{ng} / \mathrm{mL})$ to induce the proliferation of NK cells to the same dose of IL-15. In contrast to RLI that induced a strong and significant proliferation of NK cells from day 4 to day 7 of culture, IL-15 induced only minor proliferation at the end of culture (figure 4B).

Cancer cells and the tumor environment have the ability to escape NK cell recognition through the modulation of NK activating receptors and/or via the secretion 
of immunosuppressive factors. ${ }^{23}{ }^{24}$ NKp30, NKp44 and NKG2D have all been described as being able to recognize ligands expressed on tumor cells, leading to NK cell activation and the death of tumor target cells. ${ }^{25-31}$ We, therefore, investigated the effect of RLI on the expression of NK cell activating receptors, namely CD16, NKp30, NKp44 and NKG2D after treatment with RLI or IL-15. Human PBMC from healthy donors were incubated with RLI, IL-15 or medium alone for 2 days and surface expression of activating receptors was monitored by flow cytometry. As shown in figure 4C, RLI increased the surface expression of NKp30, NKp44 and at a lower level NKG2D but had no effect on CD16 expression. In addition, a strong upregulation of HLA-DR molecules was observed in the presence of RLI demonstrating the activation status of NK cells. Although IL-15 tended to increase the expression of these receptors, a significant difference was only observed with NKp44. Altogether, these data suggest that RLI is able to strongly regulate the activation of human NK cells.

\section{RLI increases ex vivo functions of NK cells from patients with cancer}

Patients with advanced NSCLC (stage IIIB/IV) have been described to have decreased NK cell functions and exhibited down-regulation of the activating receptor NKp30 in the tumor suggesting that tumor cells could escape from NK cell attack through the modulation of the NKp30 receptor. ${ }^{31}$ We, thus, sought whether RLI and/or IL-15 could restore NKp30 functions from these patients. Therefore, PBMC from five patients were stimulated overnight with medium alone, RLI or IL-15. The day after and 5 hours after matched isotype controls, NKp30 or CD16 cross-linking, we monitored by flow cytometry the intracytoplasmic expression of IFN $\gamma$ and TNF $\alpha$ in CD3- CD $56^{+}$ (NK) cells, and the cell-surface expression of Lamp-1 (CD107a), which is normally restricted to cytoplasmic vesicles but transiently expressed on the cell surface after vesicle fusion and degranulation. CD16 cross-linking has been used as a positive control for NK cell degranulation. Overnight culture was not sufficient to increase the expression of activating receptors on NK cells (data not shown), thus increased degranulation and/or cytokine production cannot be due to an augmentation of the receptor-expression on the cell surface. CD16 crosslinking led to a strong degranulation underlined by the high percentage of cells expressing CD107a, IFNy or $\mathrm{TNF} \alpha$ in the control group. Moreover, we observed a slight increase of the percentage of CD107a and TNF $\alpha$ after RLI culture but no difference could be detected with IL-15 after CD16 crosslinking. For each patient tested, RLI systematically increased the expression of CD107a $(p=0.005)$ and TNF $\alpha(p=0.013)$ when NKp30 was engaged. Although no significant difference was detected on the percentage of IFN $\gamma$-expressing cells, we cannot exclude that RLI could increase the release of IFN $\gamma$. No significant difference could be observed with soluble
IL-15 (figure 4D,E). Altogether, these data suggest that RLI is a robust inducer of NK cell functions from patients with advanced NSCLC.

\section{Discussion}

The enthusiasm around IL-15 is evident. Ranked by the NCI immunotherapy workshop in 2007 as one of the most promising immunotherapy that could cure cancer, this molecule or novel approaches based on IL-15 have since then being assessed or currently assessed in multiple clinical trials. One of these strategies was developed by Mortier et al, by generating a fusion protein between IL-15 and the sushiIL-15R $\alpha$ called RLI. ${ }^{9}$ While a phase I/Ib clinical trial is currently evaluating the safety and preliminary efficacy of RLI alone or in combination with pembrolizumab in patients with advanced/metastatic solid cancer (SC103), we aimed to further investigate the antimetastatic mechanisms of action of RLI as monotherapy in preclinical models. Our study demonstrated that RLI is more potent than IL-15 alone to reduce the number of metastases in the physiological $4 \mathrm{~T} 1$ mouse breast cancer model, consistent with previous reports for RLI or other IL-15 complexes. ${ }^{10} 32-34$

The mechanism of action leading to the diminution of lung metastases after RLI treatment remains complex. Indeed, IL-15 is a pleiotropic cytokine and numerous immune and non-immune cells can express its receptor. ${ }^{35}$ Several hypothesis can be proposed: (1) RLI could act at the primary tumor site by changing its metastatic potential (modification of the stroma of the tumor; modification of the extracellular matrix; reduction of intravasation of tumor cells; reduction of circulating tumor cells), (2) RLI could act at the metastatic niche by modulating the colonization ability of tumor cells (direct killing of tumor cells with metastatic potential; reduction of extravasation of tumor cells; reduction of chemoattraction of tumor cells) and (3) RLI could act at the metastatic niche by thwarting the development of implanted tumor cells (modification of the permissive microenvironment that contributes to metastases development; recruitment and/or proliferation and/or activation of antitumor cytotoxic effector cells). Microarray analysis data demonstrated that RLI treatment did not change the transcriptomic profile of the CD45-negative fraction of the primary and metastatic site (online online supplementary additional file 2) suggesting that the antimetastatic activity of the RLI is mainly due to the modulation of the immune system. RLI was able to modulate the metastatic niche through an increase of NK cell infiltrate accompanied with a decrease of neutrophils $\left(\mathrm{CD} 11 \mathrm{~b}^{+} \mathrm{Ly}_{6 \mathrm{G}^{+}}\right.$ Ly6 $\mathrm{C}^{\text {low }}$ ) in the lung. Interestingly, a similar observation has been recently reported with the IL-15 complex N-803. Knudson et al observed a decrease of $\mathrm{CD}_{11} \mathrm{~b}^{+} \mathrm{Ly} 6 \mathrm{G}^{\text {high }}$ Ly6C ${ }^{\text {low }}$ cells in the parenchyma and lung vasculature of 4T1-tumor bearing mice when treated with $\mathrm{N}-803$ +antiPD-L1. N-803 alone displayed a reduced number of these cells in the lung vasculature. ${ }^{36}$ Our experimental settings do not allow us to differentiate the parenchyma from 
the lung vasculature. Instead, we flushed the lungs with PBS before to harvest them. Hence, we do not expect to analyze immune cells from the lung vasculature. Additional studies are essential to elucidate the role of RLI on neutrophils. For this purpose, we propose three hypotheses. First, RLI and IL-15 might participate in the killing of neutrophils in the lung compartment. This assumption seems the least likely because IL-15 has been already described to delay neutrophil apoptosis by preventing Mcl-1 degradation and by decreasing the expression of the pro-apoptotic Bax molecule through a direct activity on neutrophils, neutrophils expressing all chains of the IL-15 receptor. ${ }^{37}{ }^{38}$ Second, IL-15-based treatment might limit the recruitment of neutrophils in the metastatic niche. IL-15/RLI might modify the cytokine/chemokine pattern in the lung and/or reduce neutrophil extravasation. In a model of T-cell deficient mice infected with Mycobacterium tuberculosis, IFN $\gamma$ has been shown to inhibit lung infiltration of neutrophils. In this model, NK cells are the major producer of IFN $\gamma \cdot{ }^{39}$ Yet, here we have shown that RLI strongly increases IFN $\gamma$-expressing cells on PMA/ ionomycin stimulation of naive NK cells. Thus, we can postulate an indirect role of RLI to limit recruitment of neutrophils in the metastatic lung following IFN $\gamma$-derived NK cells. Additional observations in non-human primates revealed a transient neutropenia after sc administration of IL-15 twice a week by Berger's group ${ }^{40}$ or after iv daily injection of IL-15 by Waldmann's group. ${ }^{41}$ Waldmann explained this neutropenia by a redistribution of neutrophils from blood to tissues. Indeed, BM examination revealed an increase cellularity including neutrophils and these cells were also present in sinusoid of enlarged livers and spleens. On the contrary, although Berger observed also a transient neutropenia, he has shown a hypocellularity in the BM after sc injections of IL-15 and proposed a lack of neutrophil production. Thus, further studies are needed to determine whether RLI may influence neutrophil production or retention in the BM of 4T1-tumor bearing mice.

Our study also demonstrated that RLI is a potent factor of NK cells in vivo with a strong accumulation and proliferation of these innate cells in all studied compartment accompanied with increased cytotoxic functions and IFN $\gamma$ production. Moreover, RLI is more efficient in inducing such effects than equimolar concentrations of IL-15 demonstrating that IL-15 trans-signaling increases the bioactivity of IL-15. These results are consistent with previous studies using other IL-15 stabilizing strategies. ${ }^{32} 42$ We demonstrated that RLI is able to induce the accumulation of $\mathrm{KLRG}^{+} \mathrm{CD} 11 \mathrm{~b}^{+}$mature NK cells. KLRG1 is a receptor with a cytoplasmic immunoreceptortyrosine-based inhibition motifs delivering an inhibitory signal following ligation with classical cadherin. KLRG1 is expressed by differentiated $\mathrm{T}$ cells, its expression is also related to non-specific activation of NK cells and late stage of maturation. ${ }^{22} 4445$ Controversial activities of KLRG1 ${ }^{+}$NK cells have been reported. Some studies showed that KLRG1 expressing NK cells produce less
IFN $\gamma$ than KLRG1 ${ }^{-}$NK cells ${ }^{21}{ }^{46}$ while in others, no difference was depicted. ${ }^{22}{ }^{45}$ In our study, the strong expression of KLRG1 was never related to diminished effector functions. The majority of splenic NK cells express KLRG1 after RLI treatment and RLI-treated NK cells show better cytotoxic capacities than IL-15-treated NK cells expressing significantly less KLRG1 (figure 3A).

Previous reports have shown that NK cells can become unresponsive on repeated administration of cytokines including IL-15 or sustained activation. ${ }^{47}$ IL-15-resistance or antidrug antibodies are serious concerns. In this study, tumor-bearing mice received repeated doses of IL-15 or RLI (four times a week for 2 or 3 weeks) with antitumor activity and NK cell modulation observed. Our pharmacodynamics studies in naive mice (two doses in a week with harvesting following the last dose) might be too short to observe NK cell hyporesponsiveness. Additional investigations on the dosing schedule would be interesting to potentially improve the antitumor activity of RLI.

Finally, our study demonstrates a potent activity of RLI on human NK cells including NK cells from patients with advanced NSCLC. Recently, we demonstrated that the levels of NCR3/NKp30 transcripts were independently associated with the outcomes in treatment-naive patients with advanced NSCLC. ${ }^{48}$ These observations are critical and promising for the activity of RLI in clinic. NK cells play an important role in immunosurveillance of cancer with the ability to kill tumor cells escaping $\mathrm{T}$ cell recognition through the down-regulation of MHC-I for instance. But tumor cells have also the ability to escape NK cell recognition through the modulation of NK activating receptors. ${ }^{24}{ }^{31}$ We demonstrated that RLI can up-regulate the surface expression of these activating receptors including NKp44 and NKp30 and increase cytotoxic functions of NK cells from patients when NKp30 is engaged. These results are consistent with previous reports using IL-15 or IL-15 complexes demonstrating increased cytotoxic functions of NK cells from patients with AML or of TGFß-induced dysfunctional NK cells. ${ }^{49} 50$

\section{CONCLUSIONS}

In conclusion, this study demonstrated the potent role of RLI in inducing modifications of the metastatic microenvironment through the increase of NK cell infiltration, maturation and proliferation while decreasing the number of lung infiltrating neutrophils, leading to the reduction of the metastatic disease. In addition, the robust activity of RLI on mouse and human NK cells from patients with advanced cancer further supports the clinical relevance of this molecule in the treatment of advanced metastatic disease.

\section{Author affiliations}

${ }^{1}$ Analyse Moléculaire, Modélisation et Imagerie de la Maladie Cancéreuse, Laboratoire d'Immunomonitoring en Oncologie, Gustave Roussy Institute, INSERM, CNRS, Paris-Saclay University, Villejuif, île-de-France, France

${ }^{2}$ Cytune Pharma, Nantes, France 
${ }^{3}$ Faculté de Médecine, Paris-Saclay University, Le Kremlin-Bicêtre, Île-de-France, France

${ }^{4}$ Centre d'investigation Clinique Biothérapie 1428, Gustave Roussy Institute, Villejuif, Île-de-France, France

${ }^{5}$ Comité de Pathologie Thoracique, Gustave Roussy Institute, Villejuif, Île-de-France, France

${ }^{6}$ Plateforme de Bioinformatique, Gustave Roussy Institute, Villejuif, Île-de-France, France

${ }^{7}$ Plateforme de Bioinformatique, Université Paris Descartes, Paris, Île-de-France, France

${ }^{8}$ U1232, CRCINA, Nantes, Pays de la Loire, France

${ }^{9}$ Faculty of Pharmacy, University Paris-Saclay, Chatenay-Malabry, France

Acknowledgements RLI was kindly provided by Cytune Pharma SAS. The authors thank Mélanie Polrot for help with animal experimentation and the PlatForm for Preclinical Evaluation (PFEP), Valérie Rouffiac and the PlatForm for Imaging and Cytometry (PFIC) and the platform of bioinformatics of Gustave Roussy. They also thank Lorna Saint Ange for editing.

Contributors $\mathrm{NC}$ and $\mathrm{DB}$ conceived the project. MD participated in the research design. $\mathrm{MD}, \mathrm{CB}$ and $\mathrm{MC}$ conducted the experiments. BB provided clinical data and study operations support. GM and NC provided bioinformatics support. MD, LC and $\mathrm{NC}$ wrote the manuscript. YJ revised the manuscript for critical intellectual content. All authors read and approved the final manuscript.

Funding This work was supported by Cytune Pharma SAS, Gustave Roussy Cancer Campus, the Institut national de la santé et de la recherche médicale (INSERM), the Direction Générale de l'Offre de Soins (DGOS), the Institut National du Cancer (INCa), SIRIC SOCRATE (INCa DGOS INSERM 6043), Agence Nationale pour la Recherche (Recherches Partenariales et Innovation Biomedicale: ANR-2011-RPIB-007-05 and MMO program: ANR-10IBHU-0001); the Agence Nationale de la Recherche et de la Technologie (ANRT), Assistance Publique des Hôpitaux de Paris (AP-HP).

Competing interests MD, DB and NC disclose a potential conflict of interest. MD received income from Cytune Pharma SAS. DB is director and shareholder of Cytune Pharma SAS. NC received grant supports from Cytune Pharma.

Patient consent for publication Not required.

Ethics approval Immune monitoring in the blood of patients was approved by the Kremlin Bicêtre Hospital Ethics Committee (no 110-08; ID RCB: 2008-A01171-54) and the Declaration of Helsinki protocols were followed.

Provenance and peer review Not commissioned; externally peer reviewed.

Data availability statement Data are available on reasonable request.

Open access This is an open access article distributed in accordance with the Creative Commons Attribution Non Commercial (CC BY-NC 4.0) license, which permits others to distribute, remix, adapt, build upon this work non-commercially, and license their derivative works on different terms, provided the original work is properly cited, appropriate credit is given, any changes made indicated, and the use is non-commercial. See http://creativecommons.org/licenses/by-nc/4.0/.

\section{ORCID iD}

Mélanie Desbois http://orcid.org/0000-0001-5503-8821

\section{REFERENCES}

1 Grabstein KH, Eisenman J, Shanebeck K, et al. Cloning of a T cell growth factor that interacts with the beta chain of the interleukin-2 receptor. Science 1994;264:965-8.

2 Carson WE, Giri JG, Lindemann MJ, et al. Interleukin (IL) 15 is a novel cytokine that activates human natural killer cells via components of the IL-2 receptor. J Exp Med 1994;180:1395-403.

3 Kennedy MK, Glaccum M, Brown SN, et al. Reversible defects in natural killer and memory CD8 T cell lineages in interleukin 15-deficient mice. J Exp Med 2000;191:771-80.

4 Lodolce JP, Burkett PR, Boone DL, et al. T cell-independent interleukin 15Ralpha signals are required for bystander proliferation. J Exp Med 2001;194:1187-94.

5 Marks-Konczalik J, Dubois S, Losi JM, et al. II-2-Induced activationinduced cell death is inhibited in IL-15 transgenic mice. Proc Natl Acad Sci U S A 2000;97:11445-50.

6 Ku CC, Murakami M, Sakamoto A, et al. Control of homeostasis of CD8+ memory T cells by opposing cytokines. Science 2000;288:675-8.
7 Cesana GC, DeRaffele G, Cohen S, et al. Characterization of $\mathrm{CD} 4+\mathrm{CD} 25+$ regulatory $\mathrm{T}$ cells in patients treated with high-dose interleukin-2 for metastatic melanoma or renal cell carcinoma. J Clin Oncol 2006;24:1169-77.

8 Cheever MA. Twelve immunotherapy drugs that could cure cancers. Immunol Rev 2008;222:357-68.

9 Mortier E, Quéméner A, Vusio P, et al. Soluble interleukin-15 receptor alpha (IL-15R alpha)-sushi as a selective and potent agonist of IL-15 action through IL-15R beta/gamma. Hyperagonist IL-15 x IL-15R alpha fusion proteins. $J$ Biol Chem 2006;281:1612-9.

10 Bessard A, Solé V, Bouchaud G, et al. High antitumor activity of RLI, an interleukin-15 (IL-15)-IL-15 receptor alpha fusion protein, in metastatic melanoma and colorectal cancer. Mol Cancer Ther 2009;8:2736-45.

11 Huntington ND, Legrand N, Alves NL, et al. II-15 trans-presentation promotes human NK cell development and differentiation in vivo. $J$ Exp Med 2009;206:25-34.

12 Huntington ND, Alves NL, Legrand N, et al. II-15 transpresentation promotes both human T-cell reconstitution and T-celldependent antibody responses in vivo. Proc Natl Acad Sci U S A 2011;108:6217-22

13 Pacheco Y, Solé V, Billaud E, et al. Despite an impaired response to IL-7, CD4+EM T cells from HIV-positive patients proliferate normally in response to IL-15 and its superagonist, RLI. AIDS 2011;25:1701-10.

14 Vincent M, Bessard A, Cochonneau D, et al. Tumor targeting of the IL-15 superagonist RLI by an anti-GD2 antibody strongly enhances its antitumor potency. Int $J$ Cancer 2013;133:757-65.

15 Vincent M, Teppaz G, Lajoie L, et al. Highly potent anti-CD20-RLI immunocytokine targeting established human $B$ lymphoma in scid mouse. MAbs 2014;6:1026-37.

16 Desbois M, Le Vu P, Coutzac C, et al. II-15 trans-signaling with the superagonist RLI promotes Effector/Memory CD8+ T cell responses and enhances antitumor activity of PD-1 antagonists. $J$ Immunol 2016;197:168-78.

17 Quail DF, Joyce JA. Microenvironmental regulation of tumor progression and metastasis. Nat Med 2013;19:1423-37.

18 Pulaski BA, Coligan JE. Ostrand-Rosenberg S: Mouse 4T1 breast tumor model. In: Current protocols in immunology, 2001Chapter 20:Unit 2022.

19 Pulaski BA, Ostrand-Rosenberg S. Reduction of established spontaneous mammary carcinoma metastases following immunotherapy with major histocompatibility complex class II and B7.1 cell-based tumor vaccines. Cancer Res 1998;58:1486-93.

20 Casbon A-J, Reynaud D, Park C, et al. Invasive breast cancer reprograms early myeloid differentiation in the bone marrow to generate immunosuppressive neutrophils. Proc Natl Acad Sci U S A 2015;112:E566-75.

21 Robbins SH, Nguyen KB, Takahashi N, et al. Cutting edge: inhibitory functions of the killer cell lectin-like receptor $\mathrm{G} 1$ molecule during the activation of mouse NK cells. J Immunol 2002;168:2585-9.

22 Robbins SH, Tessmer MS, Mikayama T, et al. Expansion and contraction of the NK cell compartment in response to murine cytomegalovirus infection. J Immunol 2004;173:259-66.

23 Ménard C, Blay J-Y, Borg C, et al. Natural killer cell IFN-gamma levels predict long-term survival with imatinib mesylate therapy in gastrointestinal stromal tumor-bearing patients. Cancer Res 2009;69:3563-9.

24 Mamessier E, Sylvain A, Thibult M-L, et al. Human breast cancer cells enhance self tolerance by promoting evasion from NK cell antitumor immunity. J Clin Invest 2011:121:3609-22.

25 Cantoni C, Bottino C, Vitale M, et al. Nkp44, a triggering receptor involved in tumor cell lysis by activated human natural killer cells, is a novel member of the immunoglobulin superfamily. J Exp Med 1999;189:787-96.

26 Moretta A, Bottino C, Vitale M, et al. Activating receptors and coreceptors involved in human natural killer cell-mediated cytolysis. Annu Rev Immunol 2001;19:197-223.

27 Delahaye NF, Rusakiewicz S, Martins I, et al. Alternatively spliced NKp30 isoforms affect the prognosis of gastrointestinal stromal tumors. Nat Med 2011;17:700-7.

28 Hecht M-L, Rosental B, Horlacher T, et al. Natural cytotoxicity receptors NKp30, NKp44 and NKp46 bind to different heparan sulfate/heparin sequences. J Proteome Res 2009;8:712-20.

29 Groh V, Bahram S, Bauer S, et al. Cell stress-regulated human major histocompatibility complex class I gene expressed in gastrointestinal epithelium. Proc Natl Acad Sci U S A 1996;93:12445-50.

30 Bauer S, Groh V, Wu J, et al. Activation of NK cells and T cells by NKG2D, a receptor for stress-inducible MICA. Science 1999;285:727-9. 
31 Platonova S, Cherfils-Vicini J, Damotte D, et al. Profound coordinated alterations of intratumoral NK cell phenotype and function in lung carcinoma. Cancer Res 2011;71:5412-22.

32 Dubois S, Patel HJ, Zhang M, et al. Preassociation of IL-15 with IL-15R alpha-lgG1-Fc enhances its activity on proliferation of NK and CD8+/CD44high T cells and its antitumor action. $J$ Immunol 2008;180:2099-106.

33 Stoklasek TA, Schluns KS, Lefrançois L. Combined IL-15/IL15Ralpha immunotherapy maximizes IL-15 activity in vivo. J Immunol 2006;177:6072-80.

34 Kim PS, Kwilas AR, Xu W, et al. II-15 superagonist/IL-15RoSushiFc fusion complex (IL-15SA/IL-15R $\alpha$ Su-Fc; ALT-803) markedly enhances specific subpopulations of NK and memory CD8+ T cells, and mediates potent anti-tumor activity against murine breast and colon carcinomas. Oncotarget 2016;7:16130-45.

35 Budagian V, Bulanova E, Paus R, et al. IL-15/IL-15 receptor biology: a guided tour through an expanding universe. Cytokine Growth Factor Rev 2006;17:259-80.

36 Knudson KM, Hicks KC, Alter S, et al. Mechanisms involved in IL-15 superagonist enhancement of anti-PD-L1 therapy. J Immunother Cancer 2019;7:82.

37 Ottonello L, Frumento G, Arduino N, et al. Differential regulation of spontaneous and immune complex-induced neutrophil apoptosis by proinflammatory cytokines. Role of oxidants, Bax and caspase-3. J Leukoc Biol 2002;72:125-32.

38 Pelletier M, Ratthé C, Girard D. Mechanisms involved in interleukin15-induced suppression of human neutrophil apoptosis: role of the anti-apoptotic $\mathrm{Mcl}-1$ protein and several kinases including Janus kinase-2, p38 mitogen-activated protein kinase and extracellular signal-regulated kinases-1/2. FEBS Lett 2002;532:164-70.

39 Feng CG, Kaviratne M, Rothfuchs AG, et al. Nk cell-derived IFNgamma differentially regulates innate resistance and neutrophil response in T cell-deficient hosts infected with Mycobacterium tuberculosis. J Immunol 2006;177:7086-93.
40 Berger C, Berger M, Hackman RC, et al. Safety and immunologic effects of IL-15 administration in nonhuman primates. Blood 2009;114:2417-26.

41 Waldmann TA, Lugli E, Roederer M, et al. Safety (toxicity), pharmacokinetics, immunogenicity, and impact on elements of the normal immune system of recombinant human IL-15 in rhesus macaques. Blood 2011:117:4787-95.

42 Chertova E, Bergamaschi C, Chertov O, et al. Characterization and favorable in vivo properties of heterodimeric soluble IL15.IL-15R $\alpha$ cytokine compared to IL-15 monomer. J Biol Chem 2013;288:18093-103.

43 Rubinstein MP, Kovar M, Purton JF, et al. Converting IL-15 to a superagonist by binding to soluble IL-15R\{alpha\}. Proc Natl Acad Sci U S A 2006;103:9166-71.

44 Sun JC, Beilke JN, Lanier LL. Adaptive immune features of natural killer cells. Nature 2009;457:557-61.

45 Fogel LA, Sun MM, Geurs TL, et al. Markers of nonselective and specific NK cell activation. J Immunol 2013;190:6269-76.

46 Elpek KG, Rubinstein MP, Bellemare-Pelletier A, et al. Mature natural killer cells with phenotypic and functional alterations accumulate upon sustained stimulation with IL-15/IL-15Ralpha complexes. Proc Natl Acad Sci U S A 2010;107:21647-52.

47 Frutoso M, Mortier E. Nk cell hyporesponsiveness: more is not always better. Int J Mol Sci 2019;20. doi:10.3390/ijms20184514. [Epub ahead of print: 12 Sep 2019].

48 Charrier M, Mezquita L, Lueza B, et al. Circulating innate immune markers and outcomes in treatment-naïve advanced non-small cell lung cancer patients. Eur J Cancer 2019;108:88-96.

49 Sanchez-Correa B, Bergua JM, Pera A, et al. In Vitro Culture with Interleukin-15 Leads to Expression of Activating Receptors and Recovery of Natural Killer Cell Function in Acute Myeloid Leukemia Patients. Front Immunol 2017;8:931.

50 Fujii R, Jochems C, Tritsch SR, et al. An IL-15 superagonist/IL-15R $\alpha$ fusion complex protects and rescues NK cell-cytotoxic function from TGF- $\beta 1$-mediated immunosuppression. Cancer Immunol Immunother 2018;67:675-89. 